\title{
Resolution of GPS carrier-phase ambiguities in Precise Point Positioning (PPP) with daily observations
}

\author{
M. Ge · G. Gendt · M. Rothacher • C. Shi · J. Liu
}

Published online: 8 January 2008

(c) Springer-Verlag 2008

\section{Erratum to: J Geod}

\section{DOI 10.1007/s00190-007-0187-4}

In Chapter 5, the first paragraph should read:

The studies will concentrate on daily solutions for precise applications in geodynamics and geodesy, where the data interval is long enough so that ambiguities are usually well estimated and the fixing decision can simply be made according to the estimates and STDs of the ambiguities (Blewitt 1989; Dong and Bock 1989; Ge et al. 2005). For positioning with short time intervals or for moving platforms, a more sophisticated search strategy, for example, the least-squares ambiguity decorrelation adjustment (LAMBDA) (Teunissen 1995; Teunissen et al. 1997), is usually implemented. The critical issue, how to estimate and apply the UPDs to obtain $\mathrm{SD}$-ambiguities with integer features, is the same. The difference is only in making the fixing decision.

The online version of the original article can be found under doi:10.1007/s00190-007-0187-4.

M. Ge $(\varangle) \cdot$ G. Gendt · M. Rothacher

Department of Geodesy and Remote Sensing,

GeoForschungsZentrum (GFZ) Potsdam,

Telegrafenberg A17, 14473 Potsdam, Germany

e-mail: maor@gfz-potsdam.de

G. Gendt

e-mail: gend@gfz-potsdam.de

M. Rothacher

e-mail: rothacher@gfz-potsdam.de

C. Shi $\cdot$ J. Liu

GNSS Research and Engineering Center,

Wuhan University, 430070 Wuhan,

People's Republic of China

e-mail: shi@whu.edu.cn

J. Liu

e-mail: jnliu@whu.edu.cn

\section{References}

Teunissen PJG (1995) The least-squares ambiguity decorrelation adjustment: a method for fast GPS integer ambiguity estimation. J Geod 70(1-2):65-82. doi:10.1007/BF00863419

Teunissen PJG, De Jonge PJ, Tiberius CCJM (1997) Peformance of the LAMBDA method for fast GPS ambiguity resolution. NAVIGATION J Inst Navig 44(3):373-383 